\title{
Isolation and identification of 4- $\alpha$-rhamnosyloxy benzyl glucosinolate in Noccaea caerulescens showing intraspecific variation
}

Rob M. de Graaf ${ }^{1,9 *}$, Sebastian Krosse ${ }^{1}$, Ad E.M. Swolfs ${ }^{2}$, Esra te Brinke ${ }^{3}$, Nadine Prill ${ }^{4}$, Roosa Leimu ${ }^{4}$, Peter M. van Galen ${ }^{5}$, Yanli Wang ${ }^{6}$, Mark G.M. Aarts ${ }^{6}$, Nicole M. van Dam ${ }^{17,8}$

1.Molecular Interaction Ecology, Institute of Water and Wetland Research (IWWR), Radboud University Nijmegen, PO Box 9010, 6500 GL Nijmegen, The Netherlands

2. Synthetic Organic Chemistry, Institute for Molecules and Materials (IMM), Radboud University Nijmegen, Heyendaalseweg 135, 6525 AJ Nijmegen, The Netherlands

3. Physical Organic Chemistry, Institute for Molecules and Materials (IMM), Radboud University Nijmegen, Heyendaalseweg 135, 6525 AJ Nijmegen, The Netherlands

4. Department of Plant Sciences, University of Oxford, South Parks Road, OX1 3RB, UK

5. Bio-organic Chemistry, Institute for Molecules and Materials(IMM), Radboud University Nijmegen, Heyendaalseweg 135, 6525 AJ Nijmegen, The Netherlands

6. Laboratory of Genetics, Wageningen University, Droevendaalsesteeg 1, 6708 PB Wageningen, The Netherlands

7. German Centre for Integrative Biodiversity Research (iDiv) Halle-Jena-Leipzig, Deutscher Platz 5e, D04103 Leipzig, Germany

8. Friedrich Schiller University Jena, Institute of Ecology, Dornburger-Str. 159, 07743 Jena, Gemany

9. Deparment of Microbiology, Institute of Water and Wetland Research (IWWR), Radboud University Nijmegen, Heyendaalseweg 135, 6525 AJ Nijmegen, The Netherlands

* Corresponding author, Tel.: +31 243652569. , Fax.: +31 243553450. E-mail address:

exorest@science.ru.nl (R.M. de Graaf) 


\begin{abstract}
Glucosinolates are secondary plant compounds typically found in members of the Brassicaceae and a few other plant families. Usually each plant species contains a specific subset of the $\sim 130$ different glucosinolates identified to date. However, intraspecific variation in glucosinolate profiles is commonly found. Sinalbin (4-hydroxybenzyl glucosinolate) so far has been identified as the main glucosinolate of the heavy metal accumulating plant species Noccaea caerulescens (Brassicaceae). However, a screening of 13 $N$. caerulescens populations revealed that in 10 populations a structurally related glucosinolate was found as the major component. Based on Nuclear Magnetic Resonance (NMR) and mass spectrometry analyses of the intact glucosinolate as well as of the products formed after enzymatic conversion by sulfatase or myrosinase, this compound was identified as 4- $\alpha$-rhamnosyloxy benzyl glucosinolate (glucomoringin). So far, glucomoringin had only been reported as the main glucosinolate of Moringa spp. (Moringaceae) which are tropical tree species. There was no apparent relation between the level of soil pollution at the location of origin, and the presence of glucomoringin. The isothiocyanate that is formed after conversion of glucomoringin is a potent antimicrobial and antitumor agent. It has yet to be established whether glucomoringin or its breakdown product have an added benefit to the plant in its natural habitat.
\end{abstract}

Keywords: glucosinolates, intraspecific variation, chemotypes, Thlaspi, Noccaea caerulescens, populations, isothiocyanate 


\section{Introduction}

Glucosinolates are a large class of sulfur and nitrogen containing plant secondary metabolites that are produced by most plant species belonging to the order Brassicales (Agerbirk and Olsen, 2012; Fahey, 2005). The core of every glucosinolate molecule is formed by a thiohydroximate group carrying two residues; an S-linked beta-glucopyranosyl moiety, and an O-linked sulfate residue (Agerbirk and Olsen, 2012). Additionally, each glucosinolate is characterized by a variable R-group. This R-group is synthesized from different amino-acids, such as leucine, valine, tryptophan and phenylalanine, and is used to further sub-divide glucosinolates into different structural groups, often referred to as aliphatic, indole and aromatic, or benzylic, glucosinolates (Agerbirk and Olsen, 2012; Fahey et al., 2001). In a recent review Agerbirk and Olsen (2012) reported that around 132 different natural glucosinolates are identified to date. For a part, the distribution of different types of glucosinolates is phylogenetically constrained due to the presence or absence of certain biosynthetic genes in the different branches of the Brassicales' evolutionary tree. For example, it was stated that glucosinolates with glycosylated R-groups appear to be limited to the Resedaceae and Moringaceae (Fahey et al., 2001). Also within plant families there is substantial variation in the ability to produce certain glucosinolates, due to evolutionary events including deletions and small-scale or whole genome duplications contributing to loss or gain of biosynthetic genes (Bekaert et al., 2012). As a consequence, each plant species has its own typical glucosinolate profile which may contain up to 37 different glucosinolates (Kliebenstein et al., 2001).

The glucosinolates, together with the $\beta$-thioglucosidase myrosinase, form a specific defence system against herbivores (Ahuja et al., 2010; Hopkins et al., 2009). In intact plants, myrosinase enzymes and glucosinolates are stored separately. As soon as plants are damaged by herbivore feeding or by artificial wounding, myrosinase and glucosinolates are mixed and react. Depending on the $\mathrm{pH}$, and on the presence or absence of specific modifier proteins, such as nitrile specifier or epithionitrile specifier proteins, the glucosinolates are quickly converted to nitriles, epithionitriles or isothiocyanates (Agerbirk and Olsen, 2012; Kissen and Bones, 2009; Kissen et al., 2009; Wittstock and Halkier, 2002). This two-component 
defence system has been coined as the "the mustard oil bomb" (Kissen et al., 2009; Ratzka et al., 2002). Especially the isothiocyanates, which also give cabbages and mustards their pungent flavour, are toxic or deterrent to a wide range of herbivores and pathogens (Brown and Morra, 1997; Hopkins et al., 2009; Park et al., 2013). Another property of isothiocyanates is that they contribute to human health. They can function as cancer preventing agents and can inhibit growth of bacteria such as Helicobacter pylori, which is the causal agent of gastritis (Fahey et al., 2002; Halkier and Gershenzon, 2006). Especially sulforaphane, the breakdown product of glucoraphanin (4-methylsulfinylbutyl glucosinolate), which is commonly found in high concentrations in broccoli, has been extensively studied and promoted because of its beneficial health effects (Fahey et al., 2002; Verkerk et al., 2009). Similarly, in many tropical countries extracts of the leaves, seeds and roots of Moringa tree species, belonging to the family Moringaceae, are used for a large range of medical uses (Eilert et al., 1981; Kumar et al., 2010). The main glucosinolate found in this tree is 4-( $\alpha$-L-rhamnosyloxy) benzyl glucosinolate or glucomoringin, a rhamnose derivative of sinalbin (Amaglo et al., 2010; Bennett et al., 2003; Gueyrard et al., 2010; Mekonnen and Drager, 2003). The isothiocyanate of glucomoringin is a biologically very active compound that is reported to have a beneficial effect on a broad spectrum of human diseases, ranging from bacterial infections to cancer (Fahey, 2005; Faizi et al., 1994; Ragasa et al., 2012).

Until now glucomoringin and structurally related $O$-glycosylated glucosinolates had only been identified in members of the Moringaceae and Resedaceae. Here we report the identification of glucomoringin and its isothiocyanate breakdown product as isolated from Noccaea caerulescens (J.Presl \& C.Presl) F.K.Mey., synonym. Thlaspi caerulescens J.Presl \& C.Presl, which is a member of the Brassicaceae. $N$. caerulescens is extensively studied because of its capacity to accumulate large quantities of heavy metals, such as cadmium and zinc, when grown on polluted soils (Assuncao et al., 2003; Leitenmaier and Kupper, 2013). For this reason, the species is used as a phytoremediator to clean soils contaminated with heavy metals due to mining or industrial activities. Several studies were performed to assess the influence of cadmium $(\mathrm{Cd})$ and zinc $(\mathrm{Zn})$ exposure and accumulation on the glucosinolate content of metal hyperaccumulators. Sinalbin and sinigrin, plus several other aliphatic, benzylic and indoyl glucosinolates 
were identified in N. caerulescens (Tolra et al., 2000) or in related species (Noccaea praecox, Thlaspi arvense) (Pongrac et al., 2008; Tolra et al., 2006). However, glucomoringin was never reported to be present ( Asad et al., 2013; Tolra et al., 2000). For this reason, we isolated the main glucosinolate peak of our N. caerulescens extracts and applied advanced NMR and mass spectrometry analyses (Agerbirk and Olsen, 2012; Bennett et al., 2006) to accurately identify the molecular structure of this glucosinolate. Furthermore, we analysed seeds and leaves from 13 different populations in Europe to study natural variation in glucosinolate profiles in this species. 


\section{Results and Discussion}

Desulfoglucosinolate extracts of $N$. caerulescens were first analysed by HPLC-PDA $(229 \mathrm{~nm})$ following standard procedures (see section 4. Experimental). In addition to sinalbin $(\mathrm{Rt}=9.3$ minutes), an unknown glucosinolate with a similar UV absorption spectrum but eluting at 10.4 minutes was detected in several of the plant populations that were analysed (Figure S1). The unknown desulfoglucosinolate as well as its intact parent glucosinolate were isolated from the respective $N$. caerulescens extracts and subjected to comprehensive NMR and mass spectral analyses to obtain the molecular structure. ${ }^{1} \mathrm{H}$ and ${ }^{13} \mathrm{C}$ NMR spectra were recorded both from the intact and the desulfated glucosinolate, resulting in the spectra as shown in Table 1 (numbering of the carbon atoms in as in Figure 1). As expected, the ${ }^{1} \mathrm{H}$ and ${ }^{13} \mathrm{C}$ NMR spectra of the desulfo- and the intact glucosinolate were similar.

In addition, the corresponding isothiocyanate (Figure 1, structure 3) of the unknown glucosinolate was produced by myrosinase treatment and purified on HPLC. ${ }^{1} \mathrm{H}$ and ${ }^{13} \mathrm{C}$ NMR spectra were recorded from the resulting product and identified as 4- $\alpha$-rhamnosyloxy benzyl isothiocyanate $(\mathrm{C}$ - atom numbering as in Figure 1, results Table 1). The $\alpha$-rhamnose conformation of the sugar moiety was confirmed according to

the J-couplings of the protons on the 1 " to 5 " position. As a reference, the ${ }^{1} \mathrm{H}$ and ${ }^{13} \mathrm{C}$ NMR spectra of sinalbin (Figure 1, structure 4) were recorded. This allowed us to distinguish the NMR peaks belonging to the glucose (present in both glucosinolates) and rhamnose (only in the unknown glucosinolate) moieties in the unknown glucosinolate (Figure 1, Table1).

Furthermore g_2DHSQCAD and 2D COSY analyses were performed on sinalbin as well as the unknown glucosinolate to study proton-carbon and proton-proton coupling (Figures S1, S2, S3). Based on these data, the unknown glucosinolate in $N$. caerulescens was identified as 4- $\alpha$-rhamnosyloxy benzyl glucosinolate.

The identification was further confirmed by high resolution mass spectrometry of the desulfated glucosinolate. LC-MS ESI analyses (positive mode) yielded an $\mathrm{m} / \mathrm{z} 491$ which corresponding to the mass 
of desulfated glucomoringin (Figure 1, structure 2). Using high resolution mass spectrometery with ESI detection in positive mode, an accurate mass of 514.13597 Dalton was obtained. This mass deviates only $0.07 \mathrm{mmu}$ from the calculated monoisotopic mass of $\mathrm{C}_{20} \mathrm{H}_{29} \mathrm{O}_{11} \mathrm{NSNa}(\mathrm{m} / \mathrm{z} 514.13590)$, a sodium adduct of desulfated glucomoringin. In these systems, where the full extract is directly inserted in the TOF-MS and not purified over a column, sodium salts are commonly observed (De Nicola et al., 2012).

Thus, the mass spectral data in combination with the NMR data unequivocally identify the isolated unknown glucosinolate from $N$. caerulenscens as 4-( $\alpha$-rhamnosyloxy) benzyl glucosinolate or glucomoringin. Even though our analytical platforms do not allow to unequivocally discriminate between the L- and D-form, it highly likely that we have identified 4-( $\alpha$-L -rhamnosyloxy) benzyl glucosinolate, or glucomoringin. We based this conclusion on the high similarity of our glucosinolate with the glucomorigin extracted from $M$. oleifera and the fact that L-rhamnose is the natural configuration of this deoxy sugar in plants (Giraud and Naismith 2000). Interestingly, glucosinolates with glycosylated Rgroups were believed to occur only in members of the Moringaceae or Resedaceae families (Fahey et al., 2001). Papers reporting the effect of metal pollution on glucosinolates always have reported sinalbin and sinigrin as the main glucosinolates in $N$. caerulescens (Asad et al. 2013, Tolra et al 2000). For this reason, we screened different accessions of $N$. caerulescens for the presence of glucomoringin. Of the 13 different accessions that we investigated, only three, all originating from $\mathrm{Zn}$ mining or smelting sites in the North East of Belgium, lacked glucomoringin and indeed contained sinalbin as the main glucosinolate (Figure 2, Table 2). All remaining accessions contained high levels of glucomoringin as well as low levels of sinalbin, which suggests that the latter may be the precursor for glucomoringin. Accessions from which we analysed both seeds and leaves showed that the presence or absence of glucomoringin is consistent among these samples: the Lellingen and Ganges accessions contained glucomoringin as a major compound in both seeds and leaves, whereas sinalbin was the major benzylic glucosinolate in La Calamine and Prayon leaves and seeds (Table 2). Interestingly, this congruency between seed and leaf profiles does not exist for sinigrin: this aliphatic glucosinolate was present in all leaves samples but was 
not detected in seeds (Table 2). We found no correlation between soil pollution and the presence or absence of glucomoringin. Instead, only the three closely related accessions from La Calamine, Plombières and Prayon lack glucomoringin, which suggests this glucosinolate polymorphism reflects a regional genetic variation rather than a relation with heavy metal exposure. The conversion of sinalbin to glucomoringin could very well be performed by a single enzyme and a single loss-of-function mutation of the gene encoding it would already render plants unable to make glucomoringin. Recently the transcriptome of $N$. caerulescens accession Ganges has been published (Lin et al., 2014), which could provide a way to identify the rhamnosyltranferase gene involved. In contrast to what has been found in Moringa spp., we could not identify the acetylated form of glucomoringin in N. caerulenscens (Bennett et al., 2003).

Given the predominance of glucomoringin in the populations we analysed, it is remarkable that this compound has never been detected before in N. caerulenscens (e.g. in Asad et al 2013, Tolra et al. 2000). At present, we can only speculate about the reason. Possibly, the genotypes that were used for the previous experiments by chance did not contain glucomoringin. However, it may also be possible that on HPLC-PDA glucomoringin has been misidentified as the UV spectra of sinalbin and glucomorigin are very similar. A broader screening effort would be needed to elucidate how widespread the presence of glucomoringin in $N$. caerulescens populations is. Because the ability to produce glucomoringin is also present in populations from heavily contaminated soils and because of the potent medical properties of glucomoringin and its isothiocyanate (Eilert et al., 1981; Fahey, 2005; Faizi et al., 1994; Kumar et al., 2010; Ragasa et al., 2012) this plant species thus may be used for phytoremediation as well as the production of medicinal phytochemicals.

It has been shown before that small changes in the side-chain structure of a glucosinolate may have severe effects on the resistance to herbivores (van Leur et al., 2008). It is as yet unknown how the ability to produce glucomoringin may affect the preference and performance of herbivores feeding on this species. Theoretically, the presence of the rhamnose on the side-chain will make the isothiocyanate that is formed 
more water soluble than comparable isothiocyanates without a sugar moiety. As a consequence, the isothiocyanate may be better taken up by herbivores or be transported over longer distances in the soil, thereby potentiating the effect of glucomoringin conversion products on pathogens and herbivores in the plant's environment. Current attempts to synthesize different glycosylated forms of sinalbin, including glucomoringin, may help to assess the role of side-chain glycosylation on the biological effect (Gueyrard et al., 2010). 


\section{Conclusions}

This is the first unequivocal report of the presence of glucomoringin in N. caerulesens, and likely also the first well-founded report on the presence of glucosinolates with a glycosylated side chain in the Brassicaceae. It has yet to be assessed if there is a specific ecological function for this type of glucosinolates, e.g. as a more potent resistance mechanism against insects. Our finding opens the possibility to use this plant species for the production of the pharmaceutically interesting glucosinolate glucomoringin in temperate climate zones 


\section{Experimental}

\subsection{Chemicals}

If not mentioned otherwise, all chemicals used in the procedures were of ACS quality or higher. Reference sinalbin (K-salt) was obtained from Phytoplan (Heidelberg, Germany).

\section{$\underline{4.2 \text { Plant materials }}$}

Seeds of $13 \mathrm{~N}$. caerulescens accessions were collected from different locations in Europe (Table 2). Of several of these accessions, plants were grown in a climate controlled greenhouse. Leaf samples of these plants were directly frozen in liquid nitrogen, freeze dried and stored at $-80^{\circ} \mathrm{C}$ until processing. Moringa oleifera leaf samples collected in New Delhi, India, were kindly provided by Dr Vartika Mathur, Sri Venkateswara College, University of Delhi, India. The air-dried samples from India were frozen upon arrival, freeze dried, ground and extracted like the other leaf samples.

\section{$\underline{4.3 \text { Isolation and analysis of the desulfated glucosinolates }}$}

The dry plant material or seeds were ground with a Retsch MM 300 mixer mill at $30 \mathrm{~Hz}$ for 1 minute. Aliquots of $50.0 \mathrm{mg}$ leaf or $2.5 \mathrm{mg}$ seed material were weighed in $2.0 \mathrm{ml}$ Eppendorf tubes after which 1.0 $\mathrm{ml}$ of a $70 \%$ methanol solution in water was added to the samples. The tubes were capped, vortexed and immediately placed in a water bath at $90^{\circ} \mathrm{C}$ for 5 minutes to stop myrosinase activity. After boiling, the tubes were placed in an ultrasonic bath for 15 minutes and centrifuged at 4500 r.p.m. for 10 minutes. The supernatant was collected and the remaining pellet was extracted once more with $1 \mathrm{ml} 70 \% \mathrm{MeOH}$ starting with the ultrasonic bath. Both supernatants were combined and added to a DEAE-Sephadex A-25 column $(5 \times 10 \mathrm{~mm})$. After the extracts were added, the columns were washed twice with $1 \mathrm{ml} 70 \% \mathrm{MeOH}$, once with $1 \mathrm{ml}$ MilliQ water and twice with $1 \mathrm{ml} 20 \mathrm{mM} \mathrm{NaOAc}$ buffer (pH 5.5). Thereafter, $20 \mu \mathrm{L}$ of aryl sulfatase solution (Sigma type H-1 of Helix pomatia) was added to the columns and flushed down with $50 \mu \mathrm{L} \mathrm{NaOAc}$ buffer $(\mathrm{pH}$ 5.5). The columns were covered with aluminium foil and incubated 
overnight at room temperature. Thereafter, the resulting desulfoglucosinolates were eluted from the columns with two times $0.75 \mathrm{ml}$ MilliQ water. The extract was freeze-dried, the residue redissolved in 1.0 $\mathrm{ml}$ of MilliQ water and stored at $-20^{\circ} \mathrm{C}$ until further analysis. Quantitative HPLC analyses of the desulfated glucosinolates were performed on a Dionex Ultimate 3000 HPLC (Dionex, Sunnyvale, CA, USA) equipped with a C-18 column (Alltima C-18, 150 x $4.6 \mathrm{~mm}, 3 \mu \mathrm{m}$; Alltech, Deerfield, IL, USA) held at $40^{\circ} \mathrm{C}$ and eluted with a linear water-acetonitrile gradient (2\%-35\% HPLC-grade acetonitrile in MilliQ water in 30 minutes). Peak detection was performed by a photodiodearray detector (PDA) with $229 \mathrm{~nm}$ as integration wavelength. Sinigrin $(63,188,375,500$ and $625 \mu \mathrm{M})$ was used as an external standard. To calculate the concentrations of sinalbin and glucomoringin based on the sinigrin reference curve, we used 0.4 as the relative response factor (see Brown et al 2003).

Isolation of the unknown ds-glucosinolate peak detected at 10.4 minutes was performed on an Agilent 1100 HPLC (Agilent, Santa Clara CA, USA) equipped with a fraction collector (G1315B). Peaks were separated on a Merck LiChrospher 100 RP-18 column $(250 \mathrm{~mm}$ x 4.6mm, $5 \mu \mathrm{m}$; Merck, Darmstad, Germany. A $6 \%$ acetonitrile solution in water $(1.0 \mathrm{ml} / \mathrm{min})$ was used for isocratic elution of the intact glucosinolates, which were detected by PDA at $229 \mathrm{~nm}$. The isolated peak had a retention time of 5.1 minutes (fraction collected 4.5-5.9 minutes).

\subsection{Isolation of the intact glucosinolate by HPLC:}

The intact glucosinolate was isolated using a modification of the method by (Agerbirk and Olsen, 2012). A total of $1.25 \mathrm{~g}$ ground, freeze-dried leaf sample was equally divided over eight 2 -ml Eppendorf tubes. To each tube $1 \mathrm{ml} 70 \%$ methanol in water was added, vortexed, followed by extraction in an ultrasonic bath for 15 minutes at $30^{\circ} \mathrm{C}$, after which the tubes were incubated in a $90^{\circ} \mathrm{C}$ water bath for 12 minutes. Thereafter the samples were centrifuged for 10 minutes at 5000 r.p.m. in a table centrifuge. The supernatant was removed and the remaining pellet was extracted once more with $1 \mathrm{ml} 70 \%$ methanol. The combined supernatants of all 8 tubes were transferred to a DEAE Sephadex A-25 column $(30 \mathrm{~mm} \times 6$ $\mathrm{mm}$ ) that was equilibrated with MilliQ. Subsequently the column was washed with $4 \mathrm{ml} 70 \%$ methanol 
followed by $2 \mathrm{ml}$ MilliQ. The intact glucosinolate was eluted with $15 \mathrm{ml} 5 \%$ ethanol in $0.5 \mathrm{M} \mathrm{KHSO}_{4}$. The eluent was evaporated to dryness with a Rotavapor and the residue was dissolved in $5 \mathrm{ml} \mathrm{MilliQ}$. The isolated intact glucosinolate was purified and desalted on HPLC. Aliquots of $100 \mu 1$ were injected on an Agilent 1100 HPLC equipped with a Merck LiChrospher 100 RP-18 reversed phase column (250 mm x $4.6 \mathrm{~mm} ; 5 \mu \mathrm{m})$. An isocratic program with $100 \%$ MilliQ flow $1 \mathrm{ml} / \mathrm{min}$ was used for separation and a broad peak with a retention-time between 8.5 and 14.5 minutes was collected. The volume of the combined fractions was reduced using a Rotary evaporator (Büchi) and further dried over $\mathrm{NaOH}$ in a vacuum desiccators.

\subsection{Preparation and isolation of the isothiocyanate}

The unknown intact glucosinolate (about $13 \mathrm{mg}$ ) was dissolved in $2 \mathrm{ml}$ buffer $\left(126 \mathrm{mM} \mathrm{Na} 2 \mathrm{HPO}_{4} \cdot 2 \mathrm{H}_{2} \mathrm{O}\right.$, $37 \mathrm{mM}$ citric acid monohydrate , $1 \mathrm{mM}$ L-Ascorbic acid, $\mathrm{pH}=6$ ). To this solution, $40 \mu 1$ thioglucosidase (1 u, Sigma-Aldrich E.C. 3.2.1.47 isolated from Sinapis alba) was added and incubated at room temperature for 2 hours. Aliquots $(100 \mu \mathrm{l})$ of the solution were injected on an Agilent 1100 HPLC equipped with a Merck LiChrospher 100 RP-18 column (see above) kept at $40^{\circ} \mathrm{C}$ and eluted as follows: flow rate $1 \mathrm{ml} /$ minute, 2 minutes isocratic $15 \%$ acetonitrile, followed by a gradient to $80 \%$ acetonitrile in 18 minutes. The fraction from 15-18 minutes was collected using an automated fraction collector. The volume of the combined fractions was reduced using a Rotary evaportator (Büchi) and further dried over $\mathrm{NaOH}$ in a vacuum desiccator.

\subsection{NMR analyses:}

All NMR spectra were recorded with a Varian Inova $400 \mathrm{MHz}$ NMR $(1 \mathrm{H})\left(100 \mathrm{MHz}\right.$ for $\left.{ }^{13} \mathrm{C}\right)$ equipped with a $5 \mathrm{~mm}$ PFG Indirect Detection Probe. About $1 \mathrm{mg}$ of the unknown compound was dissolved in $\mathrm{D}_{2} \mathrm{O}$ (Aldrich $99.9 \% \mathrm{D}$ ) or $\mathrm{CDCl}_{3}$ (Aldrich, 99.8\%D) in the case of the isothiocyanate, final concentration $<0.1 \mathrm{M}$. Proton spectra were recorded in $2-4$ minutes, ${ }^{13} \mathrm{C}$ and $2 \mathrm{D} g$ HMBC spectra in about 6 hours. 


\subsection{Mass spectrometry analysis}

LC-MS analysis of the desulphoglucosinolates was performed on a Thermo Finnigan LCQ Fleet ion trap mass spectrometer (Thermo Fisher Scientific Inc., Waltham, MA USA) equipped with the same C18 column (Altima) and a similar eluent program as used for the analytical separations of the desulfated glucosinolates. Peaks were detected using ESI in positive mode.

The exact mass of the unknown isolated desulphoglucosinolate was determined on a JEOL AccuTOF CS JMS-T100CS mass spectrometer (JEOL Ltd. Tokyo, Japan) with ESI detection in positive mode for high resolution mass spectrometry. Samples were analysed by infusion in methanol (MeOH Absolute ULC/MS, Biosolve BV, Valkenswaard, Netherlands) containing $0.1 \%$ formic acid (for MS 98\%, Fluka, Germany) and $50 \mathrm{nM}$ PPG425 (polypropyleneglycol average Mw = 425, Sigma Aldrich Chemie, Steinheim, Germany, as an Internal Mass Drift Compensator) at a flow of $100 \mu 1 / \mathrm{min}$ using an Agilent 1100 HPLC system without column installed.

\section{Acknowledgements}

We thank Dr Vartika Mathur (University of Delhi, India) for providing us with Moringa leaf samples, Andrew C. Smith for Ganges and Prayon N. caerulescens seeds and Thibault Sterckemann for Navacelles and Ardeche N. caerulescens seeds. 
References

Agerbirk, N., Olsen, C. E., 2012. Glucosinolate structures in evolution. Phytochemistry 77, 16-45. Ahuja, I., Rohloff, J., Bones, A., 2010. Defence mechanisms of Brassicaceae: implications for plant-insect interactions and potential for integrated pest management. A review. Agronomy for Sustainable Development 30, 311-348.

Amaglo, N. K., Bennett, R. N., Lo Curto, R. B., Rosa, E. A. S., Lo Turco, V., Giuffrida, A., Lo Curto, A., Crea, F., Timpo, G. M., 2010. Profiling selected phytochemicals and nutrients in different tissues of the multipurpose tree Moringa oleifera L., grown in Ghana. Food Chem 122, 1047-1054.

Asad, S. A., Young, S., West, H., 2013. Effect of Nickel and Cadmium on Glucosinolate Production in Thlaspi Caerulescens. Pak J Bot 45, 495-500.

Assuncao, A. G. L., Schat, H., Aarts, M. G. M., 2003. Thlaspi caerulescens, an attractive model species to study heavy metal hyperaccumulation in plants. New Phytologist 159, 351-360.

Bekaert, M., Edger, P. P., Hudson, C. M., Pires, J. C., Conant, G. C., 2012. Metabolic and evolutionary costs of herbivory defense: systems biology of glucosinolate synthesis. New Phytol 196, 596-605.

Bennett, R. N., Mellon, F. A., Foidl, N., Pratt, J. H., Dupont, M. S., Perkins, L., Kroon, P. A., 2003. Profiling glucosinolates and phenolics in vegetative and reproductive tissues of the multi-purpose trees Moringa oleifera L. (horseradish tree) and Moringa stenopetala L. Journal of Agricultural and Food Chemistry 51, 3546-3553.

Bennett, R. N., Rosa, E. A. S., Mellon, F. A., Kroon, P. A., 2006. Ontogenic profiling of glucosinolates, flavonoids, and other secondary metabolites in Eruca sativa (salad rocket), Diplotaxis erucoides (wall rocket), Diplotaxis tenuifolia (wild rocket), and Bunias orientalis (Turkish rocket). Journal of Agricultural and Food Chemistry 54, 4005-4015.

Brown, P. D., Morra, M. J., 1997. Control of soil-borne plant pests using glucosinolate-containing plants. Adv Agron 61, 167-231.

De Nicola, G. R., Nyegue, M., Montaut, S., lori, R., Menut, C., Tatibouet, A., Rollin, P., Ndoye, C., Zollo, P. H. A., 2012. Profile and quantification of glucosinolates in Pentadiplandra brazzeana Baillon.

Phytochemistry 73, 51-56.

Eilert, U., Wolters, B., Nahrstedt, A., 1981. The antibiotic principle of seeds of Moringa Oleifera and Moringa Stenopetala. Planta Medica 42, 55-61.

Fahey, J. W., 2005. Moringa: A review of the medical evidence for its nutritional, therapeutic, and prophylactic properties. Trees for life journal 1:5.

Fahey, J. W., Haristoy, X., Dolan, P. M., Kensler, T. W., Scholtus, I., Stephenson, K. K., Talalay, P., Lozniewski, A., 2002. Sulforaphane inhibits extracellular, intracellular, and antibiotic-resistant strains of Helicobacter pylori and prevents benzo[a]pyrene-induced stomach tumors. P Natl Acad Sci USA 99, 76107615.

Fahey, J. W., Zalcmann, A. T., Talalay, P., 2001. The chemical diversity and distribution of glucosinolates and isothiocyanates among plants. Phytochemistry 56, 5-51.

Faizi, S., Siddiqui, B. S., Saleem, R., Siddiqui, S., Aftab, K., Gilani, A. U. H., 1994. Isolation and Structure Elucidation of New Nitrile and Mustard Oil Glycosides from Moringa-Oleifera and Their Effect on BloodPressure. J Nat Prod 57, 1256-1261.

Giraud, M.F., Naismith, J.H., 2000. The rhamnose pathway. : curr Opin Struct Biol. 10, 687-696.

Gueyrard, D., lori, R., Tatibouet, A., Rollin, P., 2010. Glucosinolate Chemistry: Synthesis of O-Glycosylated Derivatives of Glucosinalbin. Eur J Org Chem, 3657-3664.

Halkier, B. A., Gershenzon, J., 2006. Biology and biochemistry of glucosinolates. Annual Review of Plant Biology, vol. 57. Annual Reviews, Palo Alto, pp. 303-333. 
Hopkins, R. J., van Dam, N. M., van Loon, J. J. A., 2009. Role of Glucosinolates in Insect-Plant Relationships and Multitrophic Interactions. Annu Rev Entomol 54, 57-83.

Kissen, R., Bones, A. M., 2009. Nitrile-specifier Proteins Involved in Glucosinolate Hydrolysis in Arabidopsis thaliana. J Biol Chem 284, 12057-12070.

Kissen, R., Rossiter, J. T., Bones, A. M., 2009. The 'mustard oil bomb': not so easy to assemble?! Localization, expression and distribution of the components of the myrosinase enzyme system. Phytochem Rev 8, 69-86.

Kliebenstein, D. J., Kroymann, J., Brown, P., Figuth, A., Pedersen, D., Gershenzon, J., Mitchell-Olds, T., 2001. Genetic control of natural variation in Arabidopsis glucosinolate accumulation. Plant Physiol 126, 811-825.

Kumar, P. S., Mishra, D., Ghosh, G., Panda, C. S., 2010. Medicinal uses and pharmacological properties of Moringa oleifera. International journal of Phytomedicine 2, 210-216.

Leitenmaier, B., Kupper, H., 2013. Compartmentation and complexation of metals in hyperaccumulator plants. Front Plant Sci 4.

Lin, Y.-F., Severing, E., te Lintel Hekkert, B., Schijlen, E., Aarts, M. G. M., 2014. A comprehensive set of transcript sequences of the heavy metal hyperaccumulator Noccaea caerulescens. Front Plant Sci 5. Mekonnen, Y., Drager, B., 2003. Glucosinolates in Moringa stenopetala. Planta Medica 69, 380-382. Park, H. W., Choi, K. D., Shin, I. S., 2013. Antimicrobial Activity of Isothiocyanates (ITCs) Extracted from Horseradish (Armoracia rusticana) Root against Oral Microorganisms. Biocontrol Sci 18, 163-168. Pongrac, P., Vogel-Mikus, K., Regvar, M., Tolra, R., Poschenrieder, C., Barcelo, J., 2008. Glucosinolate profiles change during the life cycle and mycorrhizal colonization in a $\mathrm{Cd} / \mathrm{Zn}$ hyperaccumulator Thlaspi praecox (Brassicaceae). J Chem Ecol 34, 1038-1044.

Ragasa, C. Y., Levida, R. M., Don, M. J., Shen, C. C., 2012. Cytotoxic Isothiocyanates from Moringa oleifera Lam Seeds. Philippine Science Letters 5, 46-52.

Ratzka, A., Vogel, H., Kliebenstein, D. J., Mitchell-Olds, T., Kroymann, J., 2002. Disarming the mustard oil bomb. P Natl Acad Sci USA 99, 11223-11228.

Tolra, R., Pongrac, P., Poschenrieder, C., Vogel-Mikus, K., Regvar, M., Barcelo, J., 2006. Distinctive effects of cadmium on glucosinolate profiles in Cd hyperaccumulator Thlaspi praecox and nonhyperaccumulator Thlaspi arvense. Plant Soil 288, 333-341.

Tolra, R. P., Alonso, R., Poschenrieder, C., Barcelo, D., Barcelo, J., 2000. Determination of glucosinolates in rapeseed and Thlaspi caerulescens plants by liquid chromatography-atmospheric pressure chemical ionization mass spectrometry. J Chromatogr A 889, 75-81.

van Leur, H., Vet, L. E. M., Van der Putten, W. H., van Dam, N. M., 2008. Barbarea vulgaris glucosinolate phenotypes differentially affect performance and preference of two different species of lepidopteran herbivores. J Chem Ecol 34, 121-131.

Verkerk, R., Schreiner, M., Krumbein, A., Ciska, E., Holst, B., Rowland, I., De Schrijver, R., Hansen, M., Gerhauser, C., Mithen, R., Dekker, M., 2009. Glucosinolates in Brassica vegetables: the influence of the food supply chain on intake, bioavailability and human health. Mol Nutr Food Res 53 Suppl 2, S219. Wittstock, U., Halkier, B. A., 2002. Glucosinolate research in the Arabidopsis era. Trends Plant Sci 7, 263270. 


\section{Table 1}

NMR Spectroscopic Data for desulphated Glucomoringin (2) in $\mathrm{D}_{2} \mathrm{O}$, Sinalbin (4) in $\mathrm{D}_{2} \mathrm{O}$ and for the isothiocyanate of glucomoringin (3) in $\mathrm{CDCl}_{3}$.

\begin{tabular}{|c|c|c|c|c|c|c|}
\hline & \multicolumn{2}{|l|}{2} & \multicolumn{2}{|l|}{4} & \multicolumn{2}{|l|}{3} \\
\hline & $\delta \mathrm{C}$ & $\delta \mathrm{H}(\mathrm{J}$ in $\mathrm{Hz})$ & $\delta \mathrm{C}$ & $\delta \mathrm{H}(\mathrm{J}$ in $\mathrm{Hz})$ & $\delta \mathrm{C}$ & $\delta \mathrm{H}(\mathrm{J}$ in $\mathrm{Hz})$ \\
\hline \multicolumn{7}{|c|}{ Glucose moiety } \\
\hline 1 ' & 80.9 & $4.57, \mathrm{~d},(9.0)$ & 81.2 & $4.55, \mathrm{~d},(9.7)$ & & \\
\hline $2^{\prime}$ & 71.9 & $3.17-3.30, \mathrm{~m}$ & 71.7 & $3.05-3.24, \mathrm{~m}$ & & \\
\hline $3^{\prime}$ & 77.0 & $3.17-3.30, \mathrm{~m}$ & 76.9 & $3.05-3.24, \mathrm{~m}$ & & \\
\hline $4^{\prime}$ & 68.8 & $3.17-3.30, \mathrm{~m}$ & 68.6 & $3.05-3.24, \mathrm{~m}$ & & \\
\hline 5 & 79.7 & $3.09, \mathrm{dt},(9.7,4.0)$ & 79.7 & $3.05-3.24, \mathrm{~m}$ & & \\
\hline $6{ }^{\prime}$ & 60.2 & $3.50, \mathrm{~m}$ & 60.1 & $3.48, \mathrm{~m}$ & & \\
\hline \multicolumn{7}{|c|}{ Benzylic moiety } \\
\hline 1 & 154.4 & & 154.7 & & 156.0 & \\
\hline 2 & 117.4 & $7.00, \mathrm{~d},(8.7)$ & 115.8 & $6.75, \mathrm{~d},(8.5)$ & 116.6 & $7.07, \mathrm{~d},(8.7)$ \\
\hline 3 & 129.3 & $7.18, \mathrm{~d},(8.7)$ & 129.3 & $7.11, \mathrm{~d},(8.5)$ & 128.4 & $7.25, \mathrm{~d},(8.7)$ \\
\hline 4 & 130.4 & & 126.6 & & 128.2 & \\
\hline 5 & 129.3 & $7.18, d,(8.7)$ & 129.3 & $7.11, \mathrm{~d},(8.5)$ & 128.4 & $7.25, \mathrm{~d},(8.7)$ \\
\hline 6 & 117.4 & $7.00, \mathrm{~d},(8.7)$ & 115.8 & $6.75, \mathrm{~d},(8.5)$ & 116.6 & $7.07, \mathrm{~d},(8.7)$ \\
\hline 7 & 37.2 & $3.86, \mathrm{~s}$ & 37.4 & $3.89, \mathrm{~s}$ & 48.2 & $4.66, \mathrm{~s}$ \\
\hline \multicolumn{7}{|c|}{ others } \\
\hline 0 & 154.6 & & 162.8 & & 128.3 & \\
\hline \multicolumn{7}{|c|}{ Rhamnose moiety } \\
\hline $1 "$ & 98.1 & $5.41, \mathrm{~d},(1.7)$ & & & 97.5 & $5.53, \mathrm{~d},(1.7)$ \\
\hline $2 "$ & 69.9 & $4.03, \mathrm{dd},(1.7,3.5)$ & & & 70.6 & 4.16 , dd $(1.7,3.5)$ \\
\hline $3 "$ & 70.0 & $3.86, \mathrm{dd},(3.5,7.0)$ & & & 71.5 & 3.99 , dd $(3.5,9.3)$ \\
\hline $4 "$ & 70.2 & $3.38, \mathrm{t},(9.7)$ & & & 73.4 & $3.56, \mathrm{t},(9.4)$ \\
\hline $5 "$ & 69.3 & $3.67, \mathrm{~m}$ & & & 68.6 & 3.77 , dq $(6.3,9.4)$ \\
\hline $6 "$ & 16.6 & $1.09, \mathrm{~d},(6.3)$ & & & 17.5 & $1.29, \mathrm{~d},(6.3)$ \\
\hline
\end{tabular}


Table 2

Concentration of glucosinolates in seeds and/or leaves of different Noccaea caerulescens accessions.

\begin{tabular}{|c|c|c|c|c|c|c|c|}
\hline \multirow[b]{2}{*}{ accession } & \multirow[b]{2}{*}{ location } & \multicolumn{3}{|c|}{ conc. Glucosinolates in seeds ( $\mu \mathrm{mol} / \mathrm{g}$ dry weight) } & \multicolumn{3}{|c|}{ conc. Glucosinolates in leaves ( $\mu \mathrm{mol} / \mathrm{g}$ dry weight) } \\
\hline & & sinigrin & sinalbin & moringin & sinigrin & sinalbin & moringin \\
\hline VDV: Valle de Varrados (France) & $42^{\circ} 46^{\prime} 34.56^{\prime \prime} 0^{\circ} 49^{\prime} 39.09 " \mathrm{E}$ & $68.4(12.7)$ & $11.4(2.32)$ & $111.0(12.8)$ & & & \\
\hline PON: Pontaut (Spain) & $42^{\circ} 50^{\prime} 3.05^{\prime \prime} \mathrm{N} \quad 0^{\circ} 44^{\prime} 0.23 " \mathrm{E}$ & $62.7(1.7)$ & $8.9(0.5)$ & $70.5(4.1)$ & & & \\
\hline LE: Lellingen (Luxembourg) & $49^{\circ} 59^{\prime} 28.63 " \mathrm{~N} 6^{\circ} 0^{\prime} 10.76 " \mathrm{E}$ & $67.3(3.7)$ & $17.7(1.2)$ & $51.9(5.7)$ & $<0.1$ & 4.7 & 34.6 \\
\hline NAV: Navacelles (France) & $43^{\circ} 53^{\prime} 15.1^{\prime \prime} \mathrm{N} 3^{\circ} 30^{\prime} 32.8^{\prime \prime} \mathrm{E}$ & $27.9(1.6)$ & $6.2(0.7)$ & $67.3(2.5)$ & & & \\
\hline LAN: Lanastosa (Spain) & $43^{\circ} 13^{\prime} 51.86^{\prime \prime} \mathrm{N} 3^{\circ} 25^{\prime} 57.69^{\prime \prime} \mathrm{W}$ & $44.2(5.8)$ & $6.7(1.6)$ & $13.3(4.0)$ & & & \\
\hline Ardeche (France) & $44^{\circ} 48^{\prime} 28,00^{\prime \prime} \mathrm{N} 04^{\circ} 20^{\prime} 44,80^{\prime \prime} \mathrm{E}$ & $59.2(8.2)$ & $19.1(3.4)$ & $41.5(8.2)$ & & & \\
\hline GA: Ganges (France) & $43^{\circ} 56^{\prime} 11.2^{\prime \prime} \mathrm{N} 3^{\circ} 40^{\prime} 17.2^{\prime \prime} \mathrm{E}$ & $42.4(5.7)$ & $8.9(1.5)$ & $24.1(2.9)$ & $<0.1$ & $2.1(0.6)$ & $12.8(1.9)$ \\
\hline $\begin{array}{l}\text { SF: Saint Felix de Pallières } \\
\text { (France) }\end{array}$ & $44^{\circ} 2^{\prime} 40.03^{\prime \prime} \mathrm{N} \quad 3^{\circ} 56^{\prime} 18.05^{\prime \prime} \mathrm{E}$ & & & & $<0.1$ & $0.4(0.1)$ & $6.7(1.7)$ \\
\hline $\begin{array}{l}\text { CDM: Col du Mas de l'Ayre } \\
\text { (France) }\end{array}$ & $44^{\circ} 25^{\prime} 47.52^{\prime \prime} \mathrm{N} \quad 3^{\circ} 59^{\prime} 14.07^{\prime \prime} \mathrm{E}$ & & & & $<0.1$ & $0.4(0.1)$ & $6.7(1.5)$ \\
\hline MP: Monte Prinzera (Italy) & $44^{\circ} 38^{\prime} 32.56^{\prime \prime} \quad 10^{\circ} 5^{\prime} 4.87^{\prime \prime} \mathrm{E}$ & & & & $<0.1$ & 0.1 & 0.8 \\
\hline PB: Plombières (Belgium) & $50^{\circ} 44^{\prime} 4.31^{\prime \prime} \mathrm{N} 5^{\circ} 57^{\prime} 49.52^{\prime \prime} \mathrm{E}$ & & & & $<0.1$ & 4.1 & $<0.1$ \\
\hline LC: La Calamine (Belgium) & $50^{\circ} 42^{\prime} 38.78^{\prime \prime} 6^{\circ} 0^{\prime} 37.42^{\prime \prime} \mathrm{E}$ & $43.9(6.1)$ & $78.4(6.3)$ & $<0.1$ & $<0.1$ & 4.8 & $<0.1$ \\
\hline PR: Prayon (Belgium) & $50^{\circ} 34^{\prime} 52.54 " \mathrm{~N} 5^{\circ} 40^{\prime} 0.64 " \mathrm{E}$ & $44.9(1.7)$ & $83.0(12.3)$ & $<0.1$ & $<0.1$ & 15.1 & $<0.1$ \\
\hline Moringa (india/lab) & $28^{\circ} 58.9^{\prime} \mathrm{N} 77^{\circ} 16.8^{\prime} \mathrm{E}$ & & & & $<0.1$ & $<0.1$ & 5.6 \\
\hline
\end{tabular}




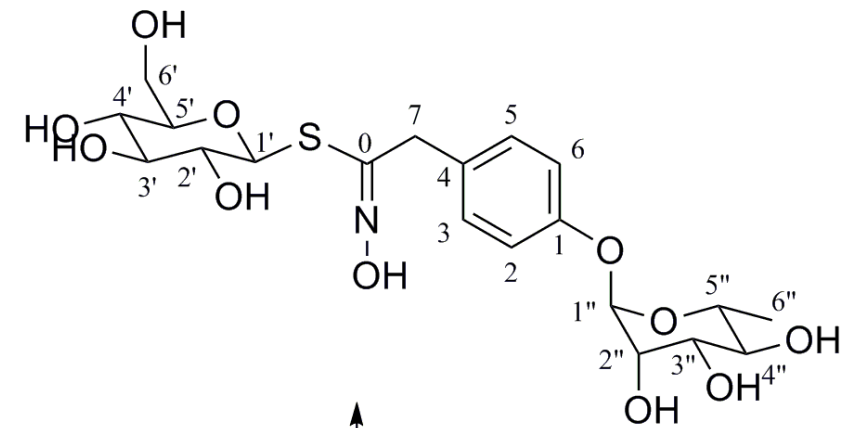

1

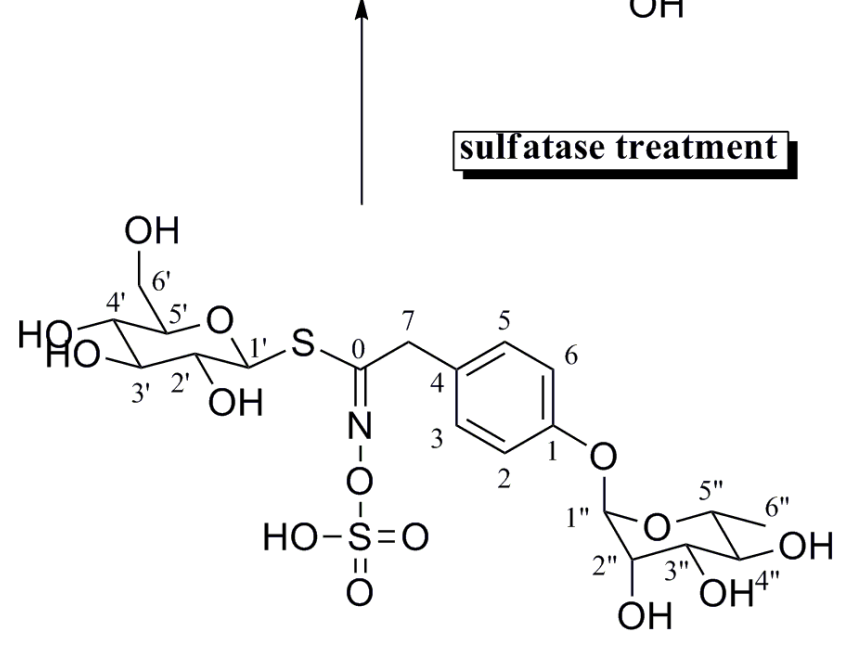

3

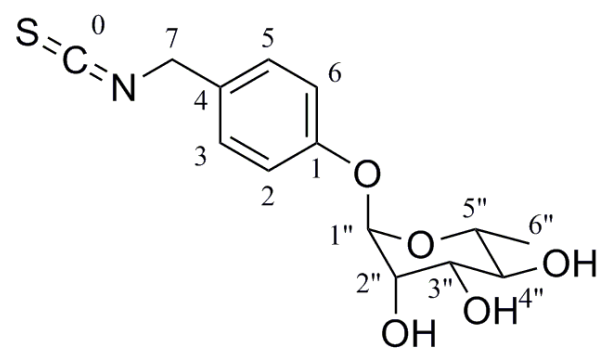

4

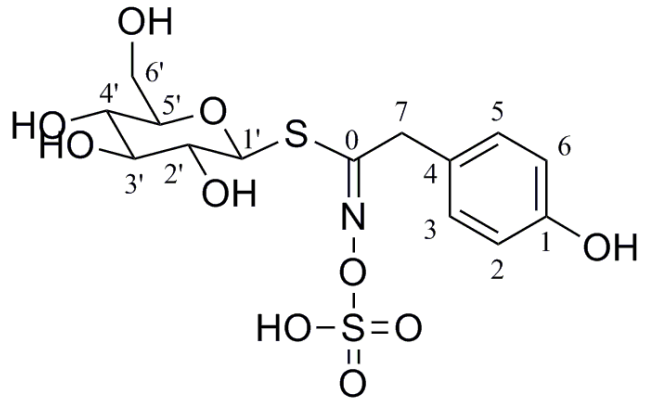


Figure 1: Schematic drawing of the reaction products formed after incubation of the 4- $\alpha$-rhamnosyloxy benzyl glucosinolate (glucomoringin) with sulfatase or myrosinase. 1: unknown glucosinolate (now identified as 4- $\alpha$-rhamnosyloxy benzyl glucosinolate) 2: desulfated glucosinolate (with carbon atom numbering) 3: corresponding isothiocyanate, 4. Sinalbin (sulfated). 


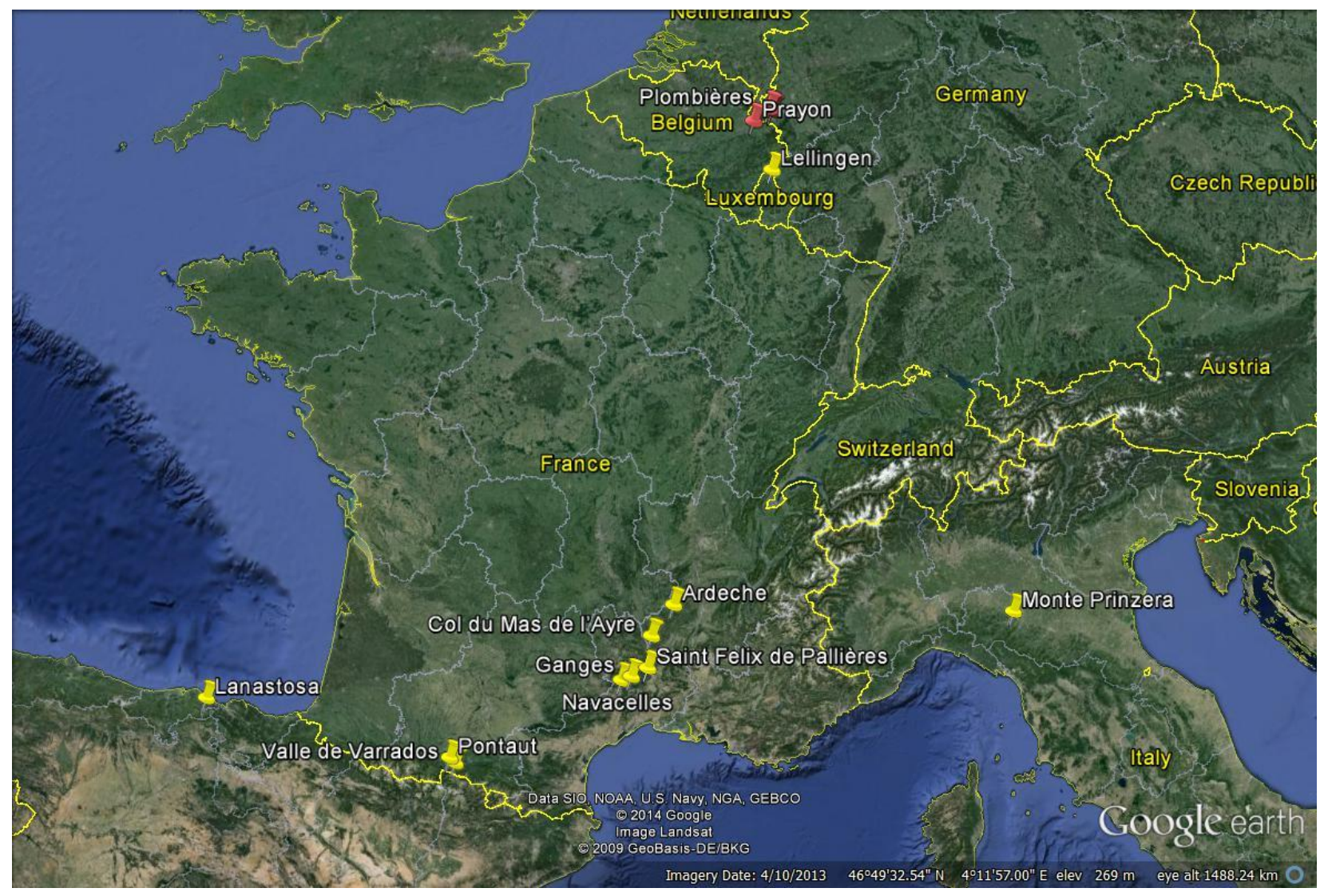

Figure 2: Map of the locations of the analysed Noccaea caerulescens accessions. The accessions indicated with a yellow pin contain glucomoringin, those indicated with a red pin do not contain glucomoringin. 

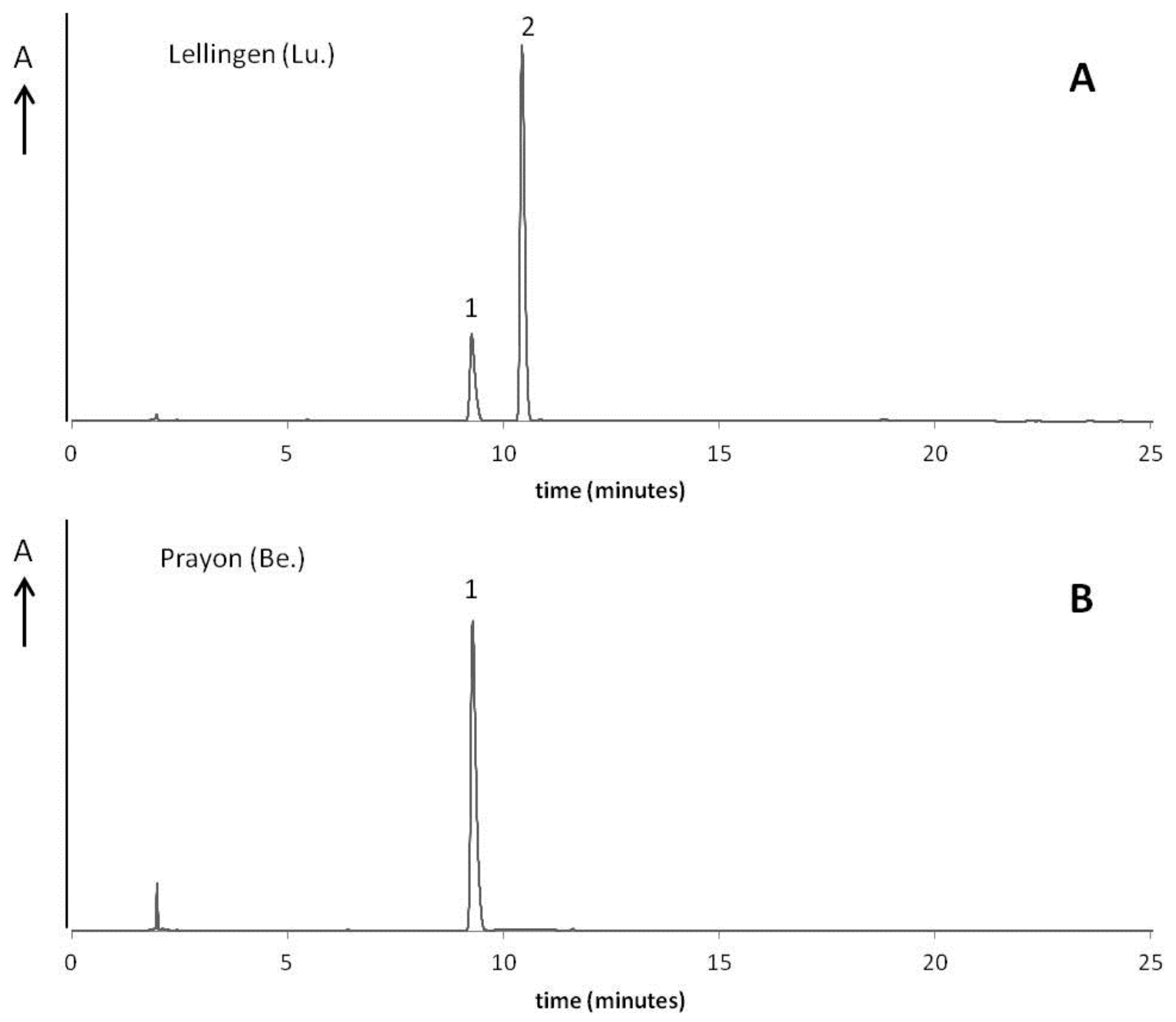

Figure S1: Selected HPLC chromatograms $(229 \mathrm{~nm})$ of Noccaea caerulescens glucosinolate extracts of leaves of plants originating from two different populations; A. Lellingen, B. Prayon. Peaks: $1=$ desulfosinalbin, 2 = desulfoglucomoringin. 


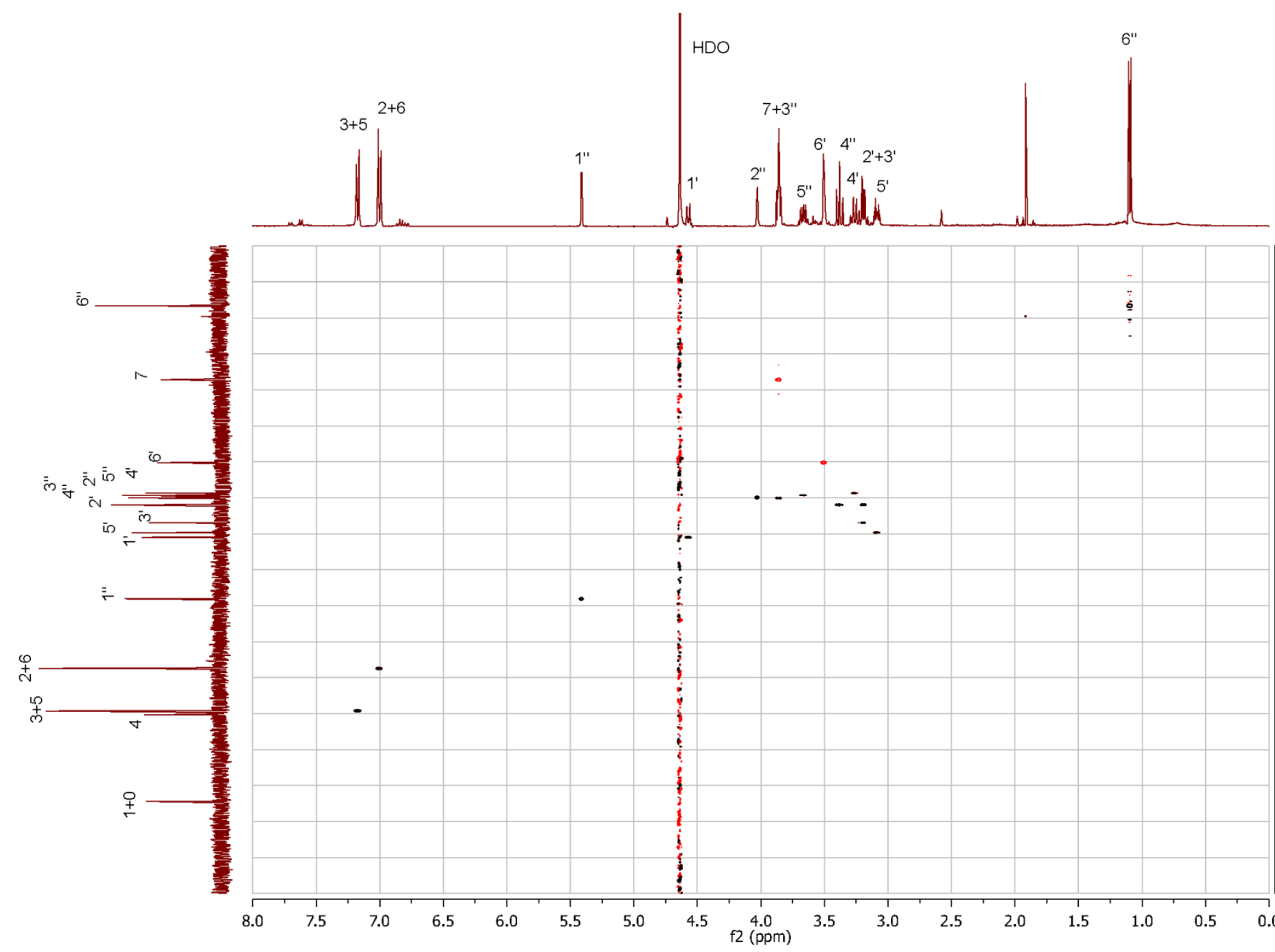

Figure S2: gHSQCAD spectrum of the unkown glucosinolate (here identified as glucomoringin). 


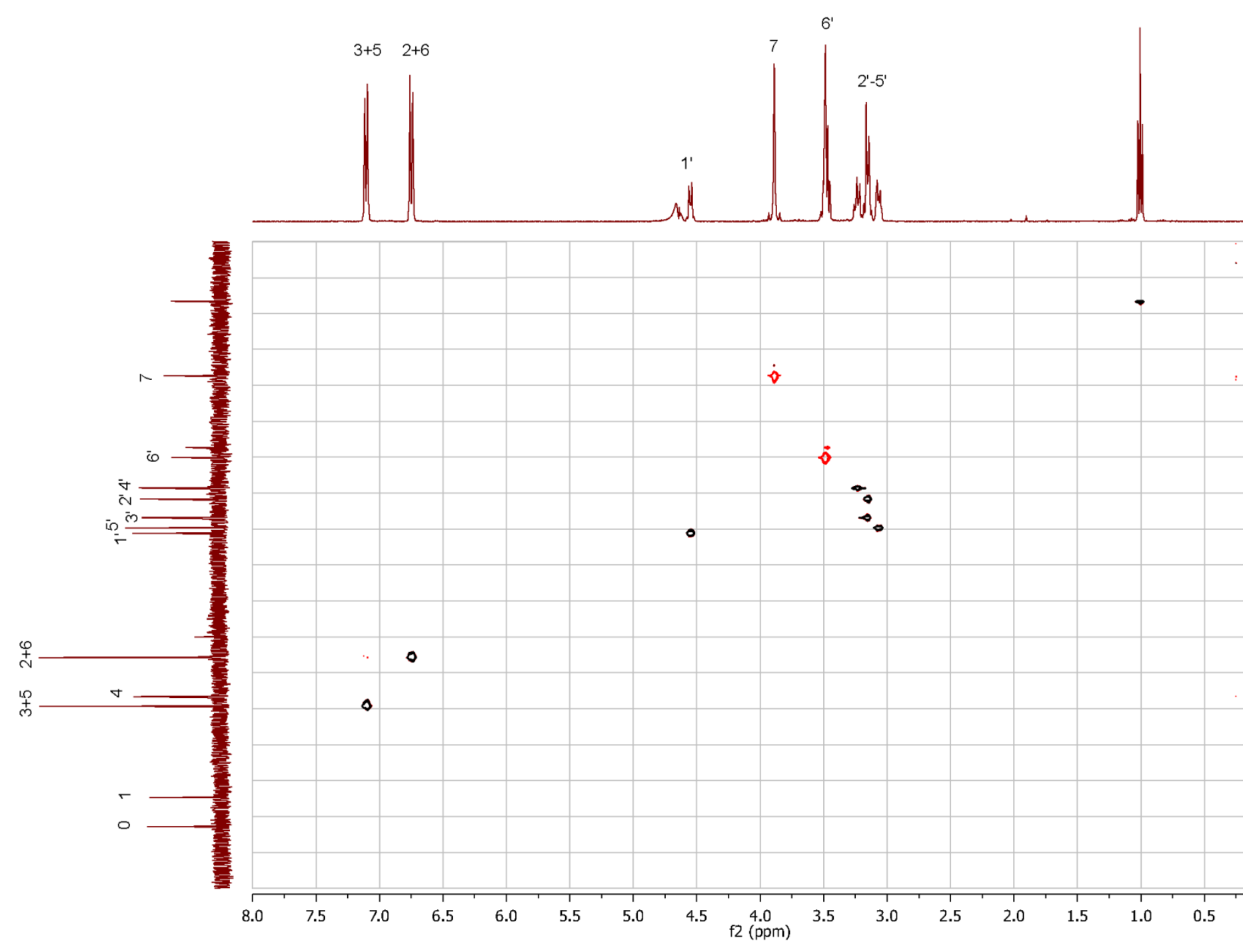

Figure S3: gHSQCAD spectrum of Sinalbin 


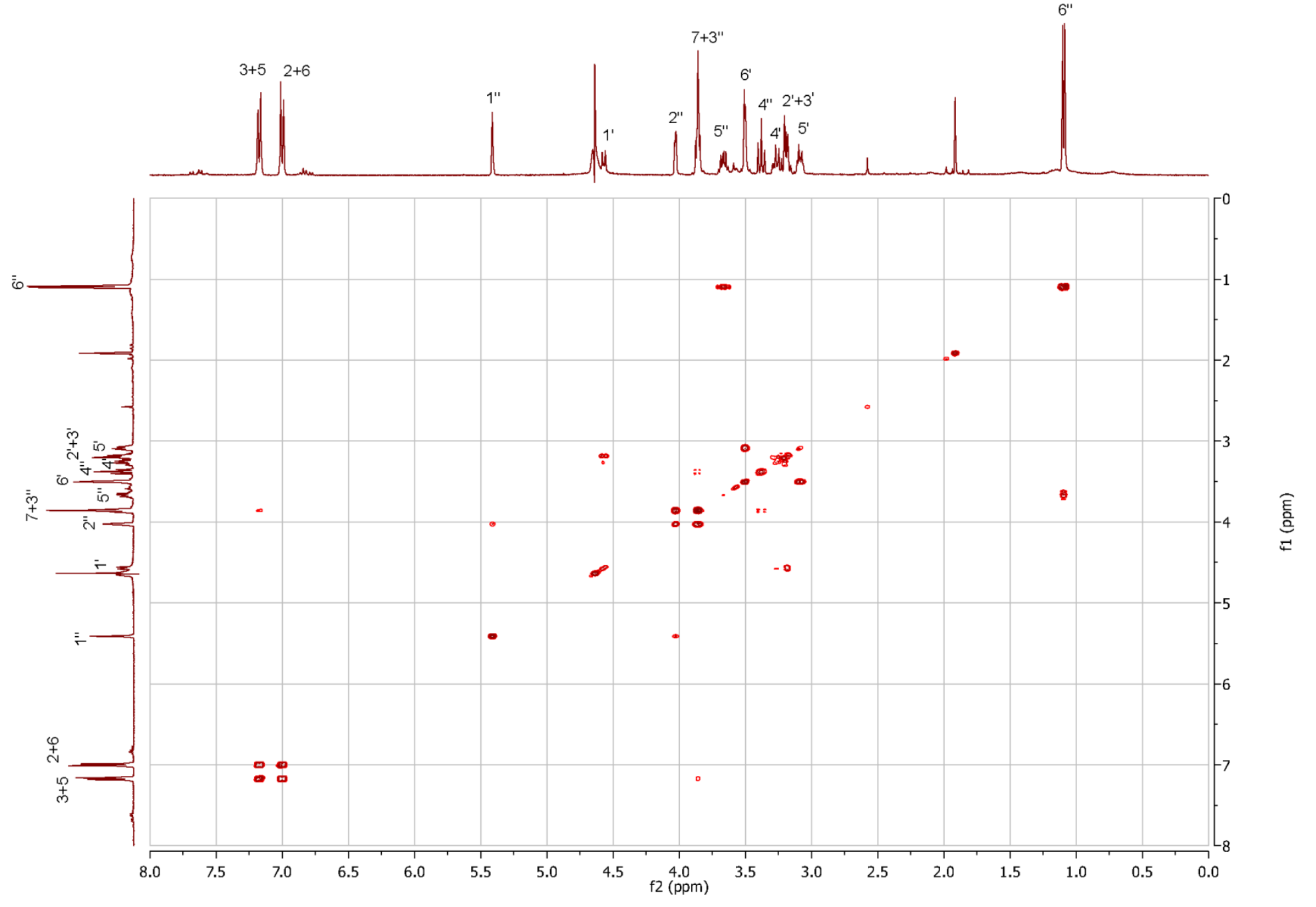

Figure S4: gCOSY NMR spectrum of the unknown glucosinolate (here identified as glucomoringin). 